\title{
Mitral Valve Prolapse and out-of-hospital cardiac arrest: A case report and literature review.
}

\author{
Antonis Ioannou ${ }^{1}$, Marios Ioannides ${ }^{1}$, Christos Eftychiou ${ }^{1}$, Theodoros Christophides ${ }^{1}$, \\ Antonis Pitsis ${ }^{2}$, Constantina Koutsofti ${ }^{3}$, Christiana Polydorou ${ }^{3}$, Gerogory Papageorgiou ${ }^{3}$, \\ Constantinos Deltas ${ }^{3}$, and Panagiotis Avraamides ${ }^{1}$ \\ ${ }^{1}$ Nicosia General Hospital \\ ${ }^{2}$ St.Luke's Hospital \\ ${ }^{3}$ University of Cyprus
}

October 17, 2021

\begin{abstract}
We present the case of a 44-year-old woman who suffered an out of hospital cardiorespiratory arrest. After six direct current shocks and 10 minutes of cardiopulmonary resuscitation she had return of spontaneous circulation and regained consciousness. Transthoracic echocardiography showed normal left ventricular ejection fraction and a mildly dilated left atrium. The mitral valve was thickened with myxomatous degeneration (Barlow's disease) and moderate regurgitation secondary to bi-leaflet prolapse. Cardiac catheterization showed no coronary artery disease while left ventriculography revealed a mildly dilated left ventricle with preserved systolic function and high-end diastolic pressures. Cardiac MRI revealed an enlarged left ventricle with mitral valve (MV) prolapse and moderate to severe mitral regurgitation (MR). There were no features suggestive of a specific cardiomyopathy other than her valvular heart disease. The patient had an uneventful hospitalization, received an implantable cardioverter defibrillator (ICD), and eventually had MV repair surgery. A genetic investigation revealed two DNA variants, one each in the MYPN and TMPO gene, substitutions of highly conserved aminoacid residues. Family segregation could not establish unequivocally their pathogenicity although the MYPN variant represents the same residue that was shown previously to be substituted by another aminoacid. In this article we also review the literature regarding similar cases and record important data for the epidemiology of the disease and the important research that has been carried out in the identification of prognostic imaging factors and the genetic background of these patients.
\end{abstract}

\section{Hosted file}

MVP_Manuscript.docx available at https://authorea.com/users/441511/articles/541993-mitralvalve-prolapse-and-out-of-hospital-cardiac-arrest-a-case-report-and-literature-review 

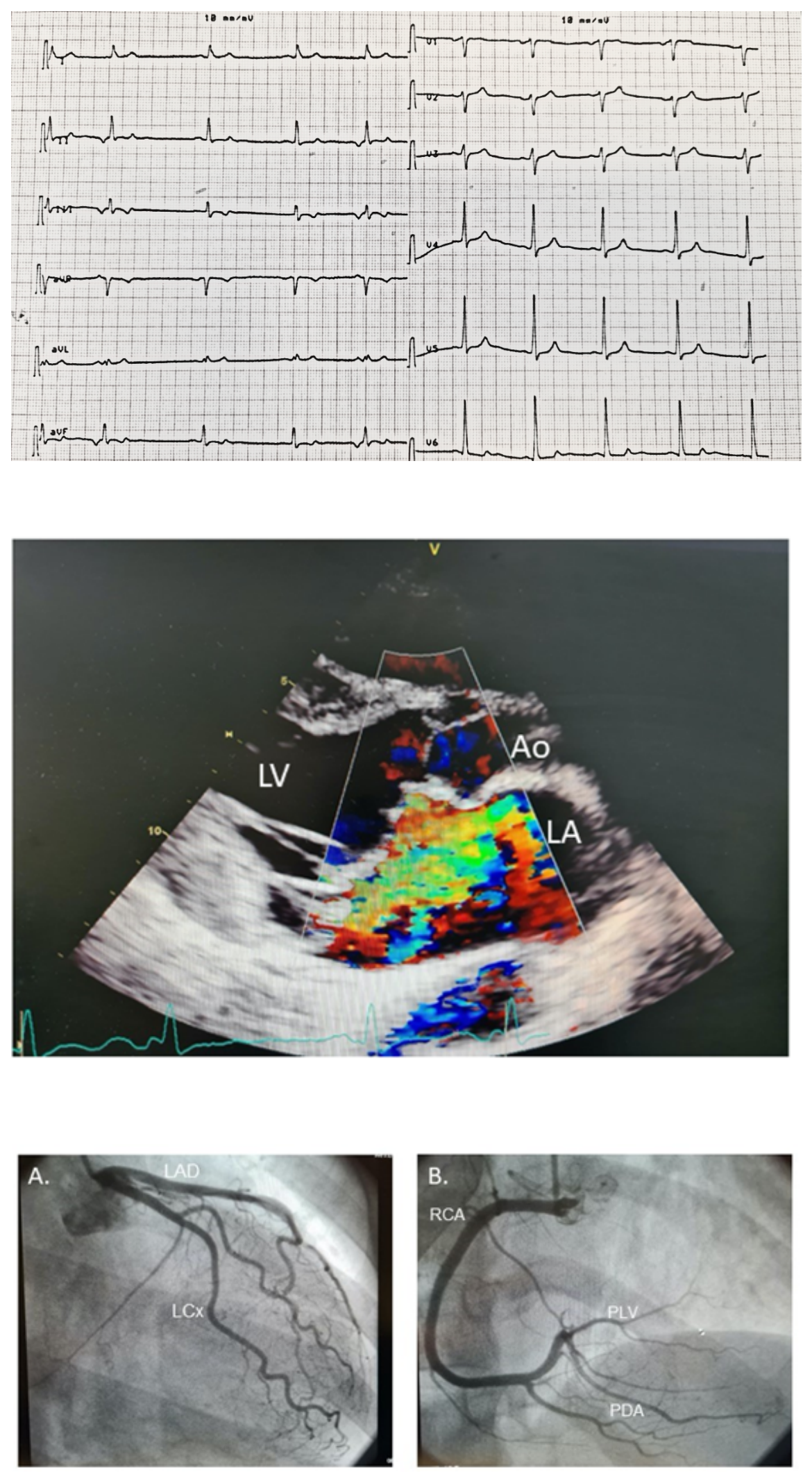

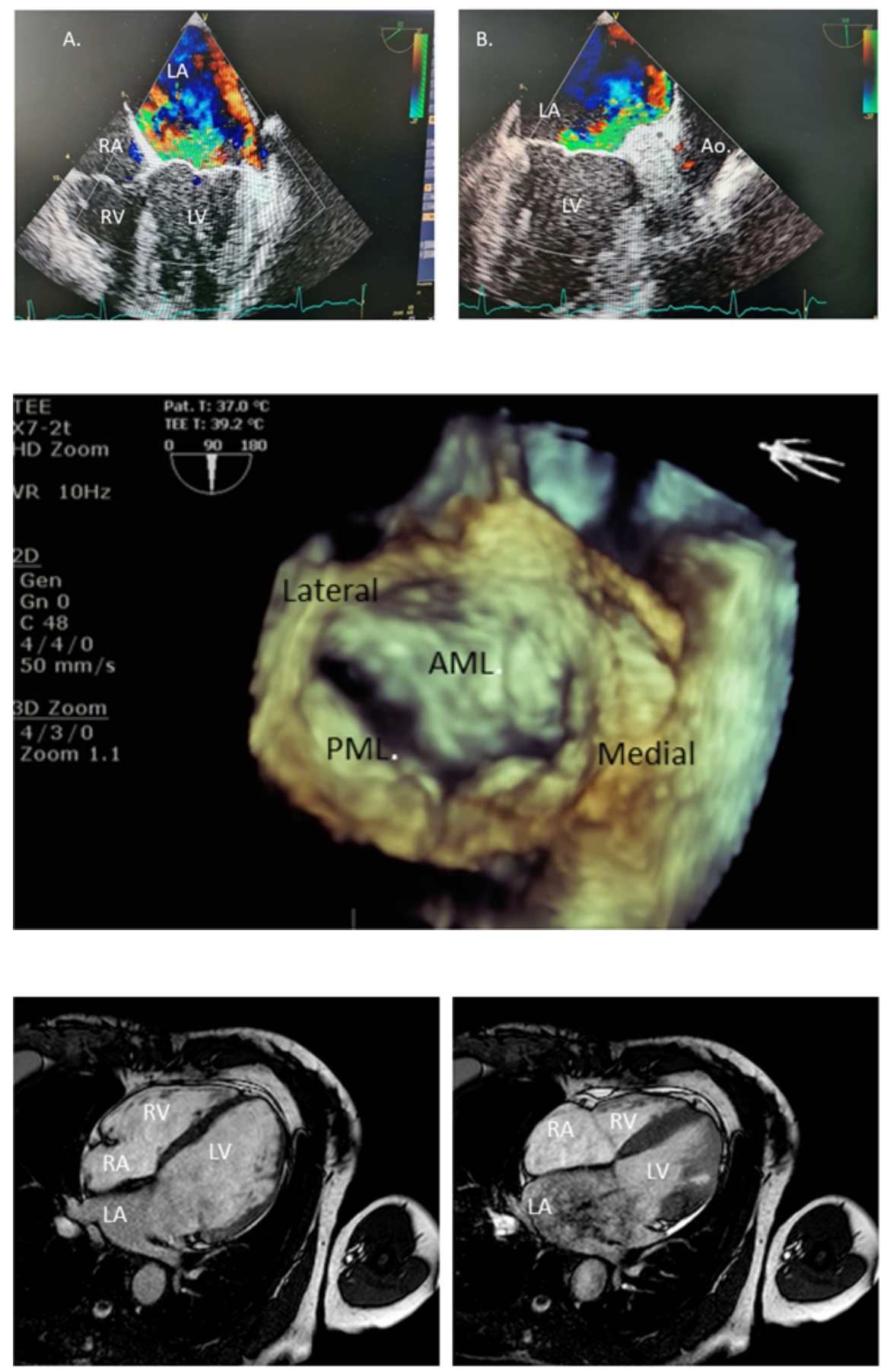


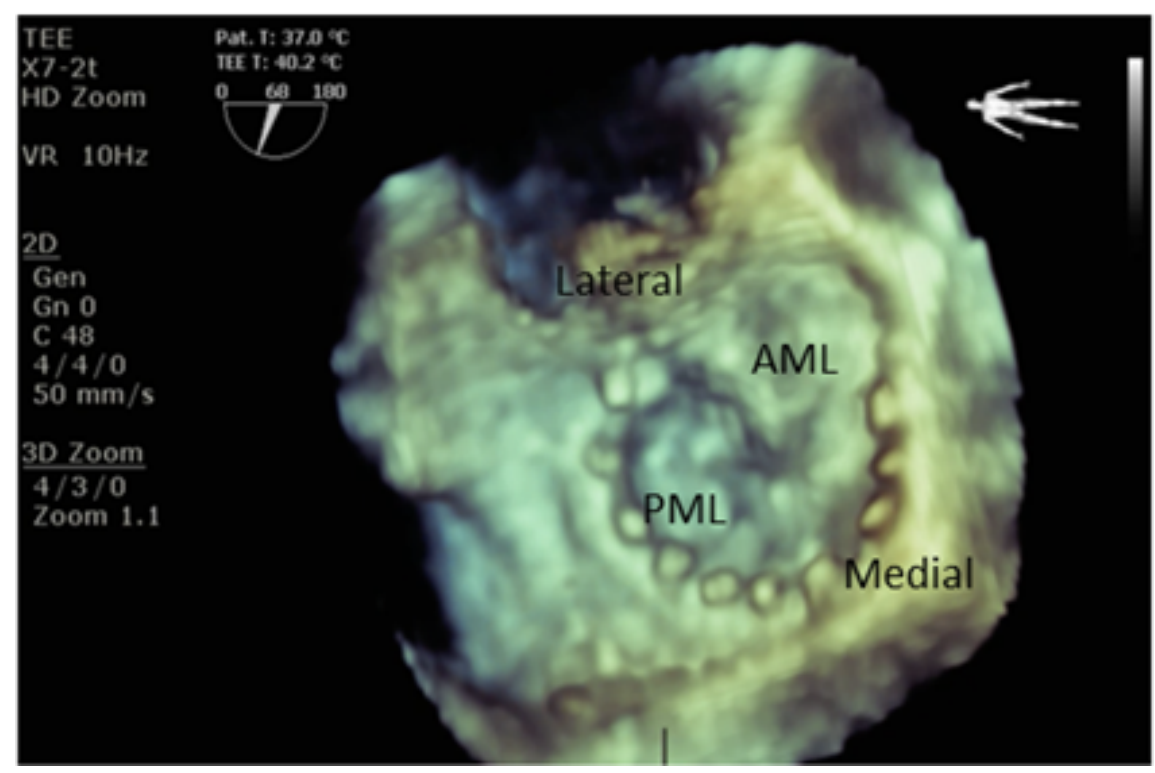

